\title{
LA CIUDAD Y EL ARTE ABSTRACTO
}

\author{
Óscar Bustamante
}

¿Qué ha cambiado? ¿La ciudad o la manera en que miramos? Ambas cosas, responde el autor de este ensayo. En el contexto de la urbe fragmentada e impulsada por sus propias fuerzas erráticas, son los edificios los que cargan de magnetismo a la ciudad. Si hasta hace poco la expresión de los edificios en la ciudad se restringía a la fachada, hoy se agrega la composición de sus volúmenes en el espacio, más allá de la necesaria respuesta al encargo y la funcionalidad. La arquitectura irrumpe así en la esfera creativa que antes era propia de los "artistas". Sorprendido de las herramientas puestas en sus manos, el arquitecto enfrenta el reto de explorar sus posibilidades. La ciudad de Bilbao, otrora industrial, sobria y algo gris, aceptó el desafío, y un inmenso animal extraño — la sede del museo Guggenheim - recaló junto a la ría. Como resultado de esta instalación sorprendente, Bilbao es otra. La ciudad contemporánea es un campo abierto, afirma el autor, a la espera de que artistas la inoculen de magia, de abstracción, a lo Guery, de que los edificios se conviertan en esculturas y los espacios en pinturas.

ÓsCaR Bustamante. Arquitecto y escritor. Estudió arquitectura en la Universidad Católica de Chile, y durante varios años fue profesor en la Facultad de Arquitectura de la misma casa de estudios. Autor de las novelas Asesinato en la Cancha de Afuera (1991) y Explicación de Todos mis Tropiezos (1995). En 2002 apareció su libro de cuentos Café Cortado. 


\section{La ciudad contemporánea: un espacio abstracto}

L ción sorprendente. En otras palabras, lo que entendíamos por ciudad se desvaloriza y se convierte en algo más complejo y difícil de codificar. Es ciudad porque en ella se habita, pero se intuye que es "otra". Es otra porque se habita de una manera diferente, ya sea porque hemos cambiado y también porque ella responde a nuestros cambios con su propia identidad.

Nuestra natural ansiedad es impulsiva, es búsqueda, voluntad de descubrimiento. El artista no sabe qué va a encontrar y anda en búsqueda de descubrir, abre espacios, puede racionalizar la búsqueda pero no sabe bien qué lo va a sorprender. Puede intuir en su trabajo que va en una dirección, pero siempre lo que descubre será una sorpresa. A lo más sabrá dónde detenerse a contemplar lo sorprendente y con ello habrá dado un paso adelante. Pero en la desvaloración del objeto conocido habrá apenas avanzado en la necesidad de sorprenderse. En esta lucha que será eterna no hay pausa. Nada es inmutable. El arte se construye desde nuestra codicia de saber. La tesis es que la ciudad como composición de múltiples identidades aisladas ahora se suma a esta vorágine y con ello irrumpe en el campo creativo formal del arte.

El vértigo del actual modo de vida basado en la movilidad impregna a la ciudad de múltiples expectativas. Millones de seres intercambiando necesidades, intentando ampliar sus recursos, cambiaron lo que hasta mediados del siglo XIX históricamente había sido un lugar de permanencia. Este proceso cada vez más acelerado hace que los habitantes ya no piensen en términos de sobremesa, sino de excitación y vértigo existencial. La movilidad que ha fragmentado las rígidas estructuras sociales y religiosas, deja al descampado a la sociedad y en este contexto inquieto, a todas luces en expansión, la expresividad es el resultado de la urgencia de dar con una identidad. El hombre, desde siempre reflejado en sus obras, presiona en busca de esa identidad y la ciudad recoge la impaciencia colectiva en la expresión de sus edificios y espacios. Cada edificio una voluntad y con una responsabilidad estética. Llegar a este punto es el resultado de múltiples factores, la mayoría de ellos no planificados, como ocurre con la mayoría de los impulsos de la ciudad contemporánea, pero básicamente se puede resumir que el automóvil con su nueva escala da origen a un nuevo orden urbano y con ello a la nueva ciudad. Como resultado de ello los edificios hoy día se han liberado de la cerrada grilla urbana que hasta hace pocas décadas restringía su expresión en la ciudad sólo a la fachada. Esto conlle- 
va un grado mayor de responsabilidad y ahora agrega a la necesaria funcionalidad, explícitamente, el factor volumétrico. Los antecesores del automóvil, como el tranvía, ya estaban anunciando el cambio feroz que tendría sobre la ciudad y sobre las artes, en gran medida todas tocadas por el nuevo fenómeno de la dinámica del desplazamiento.

La actual liberación volumétrica de los edificios es el resultado de la vía de alta velocidad que ha terminado por ser aceptada, al menos conceptualmente e introducida en las metrópolis en la medida de sus estructuras.

Otro factor de libertad viene dado por el diseño mediante el ordenador. Aquellas construcciones que hasta treinta años atrás sólo los arquitectos más capacitados eran capaces de imaginar, ahora el computador las pone a la vista en un despliegue de múltiples alternativas formales. En este contexto de búsqueda la Exposición Mundial de Bruselas en 1958 se convirtió en un hito histórico, una especie de síntesis de lo que las artes plásticas y la arquitectura habían logrado desarrollar, pero, sobre todo, lo que podría llegar a proponer. No existían los programas de diseño mediante ordenador entonces y tanto el Pabellón Phillips diseñado por Le Corbusier como el francés diseñado por Gillette, maravillaban por su libertad y capacidad de romper la línea recta que recién hacía cuarenta años había impuesto el Bauhaus. La arquitectura de esos edificios definitivamente señalaba una composición audaz, un campo que de la mano de la tecnología podía explorar y que en aquel momento no era aún una realidad evidente. De alguna manera aquellos edificios de la Exposición de Bruselas eran experimentales, una muestra de una futura conducta.

Hoy, 2004, la arquitectura, al igual que las artes plásticas, va y viene en búsquedas formales y no sería raro que en poco tiempo se vuelva a la pureza abstracta del Bauhaus; sin embargo en cuanto a las posibilidades de despliegue formal que otorga el ordenador, aún se está en los albores de su capacidad y en un mundo que busca sorprenderse todavía más.

La arquitectura es de las actividades creativas que han podido de verdad desarrollarse en estas últimas décadas, y para sintetizar esta introducción se puede afirmar que ha descubierto la abstracción formal. Lo que antes siempre estuvo en manos de los pintores y escultores, la libertad para explorar sobre las telas y mesas de escultura, como un ejercicio que no conlleva más que un deber ser estético —un juego de abstracción—, ahora lentamente la arquitectura siente la responsabilidad de componer sus volúmenes en el espacio aún más allá de su necesaria respuesta al encargo y su funcionalidad. 
Los arquitectos sienten el peso de esta novedad y sorprendidos de las herramientas puestas en sus manos exploran sus posibilidades. El campo antes propio de los "artistas", escultores, pintores, se ha ampliado a la arquitectura, y sospecho que ello conlleva un cambio monumental en el arte contemporáneo.

\section{El embrión que da origen a la liberación urbana: el automóvil}

No en vano el movimiento artístico "futurismo" nacido en Italia de la primera década del siglo veinte, se siente conmovido por la irrupción del automóvil. Es el primer movimiento que se plantea una intervención deliberada y militante a favor de la modernidad. Sus postulados eran: la máquina, la velocidad, el movimiento, la energía, la violencia. "Queremos cantar el amor al peligro, el hábito de la energía y la temeridad. Deseamos demoler los museos y las bibliotecas, combatir la moralidad y todas las cobardías oportunistas y utilitarias. No tenemos temor en declarar que el esplendor del mundo se ha enriquecido con una nueva belleza: la belleza de la velocidad. Un automóvil de carrera, con su caja adornada de gruesos tubos que se dirían serpientes de aliento explosivo... un automóvil de carreras, que parece correr sobre metralla, es más hermoso que la Victoria de Samotracia..."

En 1912 Marcel Duchamp, precursor del movimiento Dadá, pinta "Desnudo bajando la escalera", una descomposición cubista, y "Rueda de bicicleta", y afirma: "Esta máquina no tiene otra intención que la de desembarazarse de la apariencia de la obra de arte. Es una fantasía. Quiero poner fin al deseo de crear obras de arte." Duchamp desmitifica las categorías estéticas. Es el inicio de la descodificación. Lo que el automóvil con su revolución de la velocidad inicia en la ruptura del orden urbano también inicia la diáspora de la pintura.

Artistas del futurismo como Boccioni, Marinetti, Russolo, Bella, Severino, De Stijl, influencian el movimiento dadaísta —anti arte- y el constructivismo ruso, y en buena medida al surrealismo. Quieren insertarse en las masas y en la vida cotidiana. El manifiesto que resume a la pintura futurista reza: "A causa de la permanencia de la imagen en la retina, las cosas en movimiento se multiplican, se deforman, se suceden, como si de vibraciones se tratara. Así un caballo corriendo no tiene cuatro patas, sino veinte y sus movimientos son triangulares..."

La imagen es también válida para la ciudad. El andar del pie hace de la ciudad una diferente que a cincuenta kilómetros por hora a bordo de un vehículo. La escala se modifica. Nada puede permanecer igual frente a 
tal conmoción: velocidad, estruendo, imagen, perspectiva, horizonte en movimiento, inquietud.

La cuadrícula que mantuvo estabilizado el desarrollo urbano durante los dos últimos siglos, se rompe con el advenimiento del automóvil. Le Corbusier, por los años treinta, dictaba en Nueva York sus postulados de cómo esa ciudad debía reordenarse, afirmando que un rascacielos insertado dentro de la grilla tradicional de Manhattan llevaría la ciudad al descalabro. Aseguraba: "Vuestros rascacielos son muy chicos". Lo que él proponía era eliminar la malla de damero de fachada continua con objeto de densificar la ciudad mediante inmensos edificios insertos en una grilla amplia de espacios verdes, comunicados por vías elevadas. Reemplazar la altura media de aquella ciudad era exactamente lo opuesto a lo que la ciudad estaba haciendo al construir rascacielos dentro de la estructura de damero. En el fondo, el orden no cambiaba y, como señalaba Le Corbusier, un rascacielos tipo Empire State Building de cien pisos de altura, vecino de varios otros rascacielos, erigido en un sitio donde antes había un edificio de cuatro pisos, en el fondo era lo mismo de antes, con la diferencia que aumentaba el problema. La carga sobre la vereda y la calle resulta monstruosa. ¿Qué ocurre con los servicios, los estacionamientos de automóviles, el asolamiento, las áreas de esparcimiento?

La tecnología, metal y hormigón armado, había avanzado más que el campo de las posibilidades de su aplicación, esto aparte del fundamentalismo de Le Corbusier de querer rehacer Nueva York. Lo que en pintura se podía realizar con absoluta libertad sobre la tela, obviamente sobre la ciudad cargada de materia, se trata de una complejidad mayor. Indudablemente la teoría corbusiana resultaba impracticable en Manhattan, y en cualquier otra ciudad consolidada, pero en el campo de la expansión urbana era iluminadora y coherente.

Los postulados corbusianos nunca fueron plenamente practicados, aún en espacios vírgenes, y menos en áreas urbanas densamente pobladas tal como en el caso de Nueva York, pero sí eran el germen para el nuevo orden urbano. La teoría plantea la ciudad contaminada por la velocidad del automóvil que se libera del trazado de damero y la fachada continua para dar paso al edificio aislado en altura y con ello a la liberación del volumen en el espacio. Con ello cada edificio adopta un compromiso con su forma, y necesariamente con su estética, aunque el tema de la estética en ese momento estaba respondido por la función.

En síntesis, el causante que da origen a la nueva estructura urbana es el automóvil. El tiempo apremia: velocidad de desplazamientos y obviamente, el trazado de damero con bocacalles y semáforos cada cien metros resultaban un impedimento insalvable. 


\section{El orden urbano sobrepasado}

La ciudad, hasta los albores del siglo veinte, era una creación conceptualmente unitaria y sometida a lo colectivo. Dentro de este orden, los edificios tendían a la uniformidad, salvo aquellos, normalmente templos religiosos, palacios, estaciones de ferrocarril, o museos y monumentos que por su dimensión y destino resultaban únicos. Los estilos se mostraban en las fachadas y básicamente el orden urbano era un todo identificable por sobre las individualidades. Hasta Gaudí se somete en la Barcelona modernista: la casa Batlló y la mismísima casa Milá respetan que están insertas en la grilla formal de Barcelona y comparten hombros en la vereda, si bien su libertad es absoluta en todos los otros planos. Sin embargo, su rebeldía no sobrepasa las leyes y coordenadas del trazado, salvo en aquellos edificios que la grilla se lo permitía: Sagrada Familia, Parque Güell.

Arquitectos como Le Corbusier no miraban al automóvil como un elemento perturbador, más bien todo lo contrario, como un signo revolucionario que había que tomar en cuenta y sobre todo adelantarse en las ideas para evitar lo que ellos intuían como lo peor que podía ocurrirles a las ciudades: la conurbación, en síntesis, las megalópolis y el enjambre de partículas ocupadas por el trazado tradicional. En esto fueron visionarios y todos los temores se cumplieron. La ciudad no se adaptó a tiempo a las condiciones del automóvil o bien no encontró alternativas adecuadas de transporte que lo reemplazaran del todo, tal como el tren subterráneo que requiere de otros complementos.

Pensar en la eliminación del automóvil aún es impensable dado de que se trata tal vez del icono más representativo de los nuevos tiempos. Está fuera de escala en la mayoría de las ciudades y en los pocos casos que lo ha acogido - llámese Los Angeles en California- la solución es altamente discutida, aduciendo que es una ciudad desprovista de alma, sin plazas, sin veredas, circunscribiendo al ciudadano a centros aislados en una inmensa red de vías. Y no es del todo así, porque los barrios conectados por las vías disponen de centros urbanos de intensa vida urbana en sus espacios destinados al peatón y al encuentro cívico. En todo caso es efectivo que se trata de una conurbación en donde la presencia avasallante de las vías ha creado un entorno deshumanizado. Pero está en una buena medida resultante de su propia lógica.

La mayoría de las ciudades de estructuras urbanas consolidadas se desarrollan utilizando incrustaciones de vías de alta velocidad para desahogarlas; sin embargo, a pesar de que la grilla urbana es más libre que el tradicional damero, menos rígida, en el fondo es similar. 
El concepto corbusiano básicamente proponía lo que en buena medida podría equivaler a ciudades satélites de tamaño autosuficiente, esparcidas en el campo y vinculadas por vías que podían acoger plenamente la velocidad del automóvil sin contaminar las metrópolis existentes, ya en el límite de su extensión ideal. La idea no se pudo nunca poner en práctica plenamente, y los casos que se construyeron, especialmente Brasilia, son ciudades que sólo lo recogen parcialmente. Le Corbusier proponía una grilla de estas ciudades satelitales las que se apoyarían unas a otras y a distancias de no más de veinte minutos en automóvil. Estos satélites acogerían las actividades básicas: trabajo en una, habitación en otra. La villa mayor - un edificio de gran altura o un conjunto de ellos, los menos posibles- acogía la habitación y la recreación. La teoría tenía una lógica irrefutable pero su puesta en práctica era una empresa colosal, económicamente inabordable. Lo que ocurrió fue que la ciudad comenzó a aplicar su concepto sólo parcialmente. Como ejemplo, por los años setenta en el barrio La Defense en los extramuros de París, se da inicio a un proyecto planificado a partir del año 1958 para la remodelación y desarrollo del barrio del mismo nombre y que tendría como hito de atracción una monumental plaza de encuentro cívico circundado por edificios de gran altura. El proyecto dio origen a una gran controversia, puesto que rompía con la línea homogénea de la altura media de París, y hubo intentos de circunscribirlo a sólo treinta y cinco metros de altura, con lo que se perdería ese objetivo de convertirse en un monumento. El conjunto - hito-, ubicado en la continuación axial del Arco de Triunfo, debería tener una presencia tal que pudiese ser observado desde cualquier punto de París y con ello, al igual que la Torre Eiffel cien años antes, reafirmar la presencia de París en la vanguardia de la arquitectura. Finalmente se impuso esta idea y se llamó a un concurso para el hito, que resultó ser un edificio a la manera de un arco de colosal dimensión.

Básicamente el orden urbano de París no se modifica y La Defense es sólo otro barrio de París con una volumetría que es la contraposición de una ciudad homogénea de seis a ocho pisos de altura. Pero independiente de ello, quedó en escena una nueva dimensión. El gran hito visual, una especie de catedral de Chartres asomándose en el horizonte. Los edificios de gran altura otorgaban una nueva espacialidad.

La intención de la obra es pionera en ese aspecto. Un fenómeno de creación con raíces estéticas a la manera de la catedral gótica. Hay en ello una aspiración de elevación espiritual: vale decir, la obra se edifica para conmocionar el espíritu ya sea por su altura, por su volumetría, por su ansiedad cósmica. Además hay una intención de respuesta urbana a los 
desafíos planteados por Le Corbusier. Concentración de actividades: oficinas en altura, ministerios públicos, servicios en la base; recreación en la plaza: comercio, cultura, esparcimiento; el automóvil separado del peatón, estaciones de metro vía, terminales de buses, estacionamientos en los subterráneos.

El caso de La Defense es una excepción, una composición urbana que más allá de resolver los problemas de desarrollo de la ciudad, pone énfasis en que debe componer la ciudad espacialmente, esto es, realzarla. Para ello, lo que los franceses llaman ser una ventana para el mundo, un moderno Arco de Triunfo. Para los parisinos esta nueva dimensión era una ventana a lo desconocido, una abstracción.

En la mayoría de los casos el volumen espacial todavía resulta ser un residuo del que no se recogen respuestas sociológicas. Este fenómeno no se contradice con la voluntad de composición que cada arquitecto impone a su creación, y siempre va a existir un anhelo de coherencia -ello sobre todo- - y una íntima finalidad de dar con la belleza, aunque siempre sometida a lo que aún es una máxima impuesta por el Bauhaus: responder a la función y a lo que el arquitecto norteamericano Louis Sullivan antes ya había anunciado: "Form follows function", en el fondo una gran frase que expresaba una nueva manera de acercarse a la realidad y en gran medida a ampliar la mirada al arte. Más tarde el axioma de Mies Van Der Rohe "less is more", una frase derivada de aquella de Sullivan, se grababa al fuego para las generaciones de arquitectos que construyeron la segunda mitad del siglo veinte. Ya no era posible hacer decorados en los dinteles en edificios de cincuenta pisos, de la misma manera que coronar un avión o a un automóvil de carrera con guirnaldas.

Algo de la intención de composición urbana dio origen a las Torres de Tajamar en Providencia, por los años setenta del siglo pasado. La intención de la obra era convertirse en hito y congregar en su plaza un lugar de encuentro e intercambio alimentado por las actividades comerciales y los usuarios de las torres bajando a participar del entrecruce de actividades. La plaza como lugar de encuentro cívico era el eje arquitectónico. La escala del conjunto resultó insuficiente, una versión minúscula del concepto corbusiano: primero que nada, el conjunto estaba ligado directamente a la red urbana existente, vale decir, se trataba de un cuerpo de mayor dimensión que lo usual en Santiago, pero no un centro atractivo y autosuficiente como hoy día lo es, por ejemplo, el Parque Arauco o El Alto Las Condes, autosuficientes de por sí dadas su identidad e intensidad comercial. Las Torres de Tajamar fueron succionadas por la grilla urbana inmediata, sin embargo su presencia coronando el ex Parque Japonés aún se sostiene como un refe- 
rente en la ciudad. En contraposición con la fachada continua, que era la manera de instalarse de las casas y edificios que conformaron la ciudad colonial y sus prolongaciones, las Torres de Tajamar son un pincelazo de las teorías corbusianas en nuestra capital. El proyecto en su esencia es un fracaso; sin embargo, tal vez lo que los arquitectos no se propusieron, sigue vigente. Aún las torres de Tajamar se sostienen como seña espacial y tal vez sólo se les puede reprochar que no llevasen a cabo lo que en su volumetría y escala urbana debían haber tomado en cuenta: expresividad. Ello queda en evidencia cuando en plaza Italia se instala el edificio de la Telefónica y su volumen es imposible de ser obviado. Su escala lo convierte en hito, si bien su expresividad aún no atiende los códigos de la abstracción.

A otra escala, Brasilia, concebida como una ciudad cívica, aún es un desierto de la que sus usuarios escapan cada vez que se suma un fin de semana largo. Brasilia se destaca no como ciudad sino más bien como fenómeno de diseño, a la manera de una composición que tiene algo de la esencia de la creación pictórica. Naturalmente, la composición tiene una base en la funcionalidad, sin embargo es la volumetría puesta en el espacio lo que se destaca. Se dice de Brasilia que sólo hay vida en los barrios que nacieron como campamentos para los obreros que viajaron a construirla y que luego permanecieron en esa lejanía. Sin embargo perdura el escenario de edificios aislados en un campo, a la manera de colosales esculturas vinculadas por vías liberadas de las veredas y semáforos $\mathrm{y}$, si bien se critica su deshumanización, asunto discutible, puesto que fue concebida como capital política de Brasil, aún se sostiene como un fenómeno volumétrico y cada edificio es analizado por su expresividad.

La primera vía de alta velocidad de Santiago fue la avenida Kennedy. Si bien era apenas una conexión entre Américo Vespucio y avenida Las Condes, rodeada de terrenos eriazos, sirvió para abrir el escenario de la cordillera. Desde el automóvil aparece una nueva dimensión espacial que ahora con los edificios que la flanquean se hace evidente. En ese tramo la ciudad se asoma en una dimensión escénica donde se valora el escenario del colosal cerro El Plomo. En ese escenario, los edificios tienen una responsabilidad con el diseño. Vale decir que aún la arquitectura no se hace cargo de su nueva escala, de su impacto en la abstracción, de la descodificación formal. La respuesta a la función ha adquirido un nuevo componente de complejidad que es ahora inherente al espíritu ávido de expresividad de este tiempo. Eso de que "si respondes a la función das con la belleza" ya no es suficiente: la belleza es lo que en sí es bello, y eso es 
incodificable salvo si — como en la concepción de una obra de arte— se dé con la tonalidad, con la respuesta al concepto que da origen al proyecto, con la coherencia de los elementos con los que se trabaja en lo propuesto, lo que en sí mismo es coherente. No es una certitud, pero se intuye que la arquitectura es capaz de transponer la barrera que hasta hace poco era campo exclusivo de la pintura, eso de manejar a su arbitrio la forma, supeditándola a una abstracción, sometiéndola a una necesidad expresiva superior, a la obra de arte, aquello que aún hoy día se va a observar a las salas de museos.

\section{La nueva identidad urbana: el edificio}

La mirada desde la terraza del parque Güell sobre la ciudad de Barcelona, con el Mediterráneo de telón de fondo, da la sensación de un maravilloso cuadro abstracto, pero es el templo de la Sagrada Familia lo que destaca como el hito preponderante de la obra. Gaudí entendió lo que ese templo religioso podía aportar a la mística de Barcelona, que sin él, o mejor dicho, que con el templo la ciudad era "la ciudad".

Es la ciudad la que se abraza al templo, de la misma manera que los andariveles, el mar y los cerros que la circundan. El cuadro además cambia, se deshace y se recompone con el paso de las nubes y la lluvia.

Algo parecido ocurre con la visión de Manhattan desde un ferry que cruza desde Brooklyn. Las Torres Gemelas eran el centro de la perspectiva con la luz rebotando en los cristales. El nuevo edificio que las va a reemplazar tiene la responsabilidad urbana de recomponer Manhattan. Un cuadro, una sensación estética poderosa.

¿Qué ha cambiado? ¿La ciudad o la manera que miramos? Ambas cosas y como señalaba Kandinsky magistralmente: "El arte no reproduce lo visible, sino que lo hace visible...", y da la sensación que el alma ciudadana contemporánea colectiva ha comprendido, aunque sólo sea intuitivamente, tamaña verdad.

De pronto la ciudad se nos hace presente desde el punto de vista de una composición total. En otras palabras, la ciudad ha tomado una dimensión tal que la reconocemos como una enorme composición. Paralelamente nuestra sensibilidad capta que hay en el aire de las metrópolis y grandes ciudades un aroma a animal desconocido. La respuesta es que ahora la ciudad se revela desde nuevos puntos de vista: desde las vías abiertas que permiten la nueva mirada; desde el avión en que la perspectiva es amplia y muestra la totalidad y sus límites. 


\section{Museo Guggenheim}

La conciencia urbana de nueva identidad se expresa con plenitud en edificios tales como el museo Guggenheim de Bilbao.

Habría que señalar que Bilbao era una ciudad industrial, sobria y algo gris que aceptó el desafío de instalar una obra de la vanguardia tecnológica y avanzada en el diseño junto a la ría en lo que era una área amorfa y sin un destino urbano definido. Como resultado de esta instalación sorprendente, se hizo necesario ampliar el aeropuerto para recibir el nuevo flujo de turistas. Ahora se visita Bilbao por razones culturales. Es otra Bilbao.

Lo interesante de este cambio reside en que quienes impulsaron este edificio tenían conciencia de que mediante la introducción de una obra emblemática podían efectuar un cambio trascendente en el ser existencial de la ciudad, de alguna manera cambiar su destino. Vale decir, la conciencia de que algo muy extraordinario la podía revitalizar.

Los habitantes no pueden substraerse a que Frank Gehry los inoculó de curiosidad. Me imagino que la torre Eiffel hizo algo parecido en París. Claro que París desde hacía ya bastante tiempo tenía conciencia de que era ciudad, vale decir, venía desde mucho tiempo definiendo su aspiración a ser admirada, algo más que un lugar que se quiere y donde se habita. Los parisinos la aman porque con ella se valoran: es decir, la miran con la admiración de un hijo destacado. Una de las condiciones admirables es su orden urbano, su connotación histórica, pero sobre todo por sus íconos arquitectónicos: Notre Dame, la Tour Eiffel, La Defense y su permanente búsqueda de la vanguardia. No en vano el Louvre, por sobre su patrimonio histórico, renace con la pirámide de cristal.

El caso de Bilbao, sin embargo es más relevante, dado que básicamente se trata de una obra quien la revitaliza, si bien las estaciones del metro de Foster y el nuevo aeropuerto se suman al cambio de imagen.

En este orden de cosas no está claro si Granada tenía real dimensión de sí misma hasta que Washington Irving reveló la Alhambra. En todo caso Granada se sostiene con su encanto, independiente del edificio árabe, sólo que para los efectos de este estudio la carga de su estratificación urbana histórica, al igual que Córdoba con su barrio judío y emblemática mezquita, no requiere y tampoco quiere de un cambio de identidad. Si se está satisfecho con lo que nos rodea, no hay inquietud y sin inquietud no se busca. Sin búsqueda no hay descubrimiento.

$\mathrm{El}$ asunto es bastante complejo. Influyen múltiples factores para el fenómeno de la ciudad contemporánea asociada al arte abstracto. La ciu- 
dad, representada hoy día por el afán expresivo de sus edificios expuestos en el paisaje urbano y recién consciente de su potencialidad expresiva, es un campo abierto, un colosal espacio pictórico. Vale decir, una nueva escala de búsqueda. Los arquitectos del período modernista intuyeron el potencial pero siempre abocados a obras únicas, llámese la Sagrada Familia en Barcelona, como hitos de congruencia dentro de un espacio consolidado. La diferencia es que ahora la tela está limpia, y la composición no tiene referencias. La ciudad fragmentada e impulsada por sus propias fuerzas erráticas, es campo abierto. No hay por el momento capacidad de ordenar un todo, salvo el de sobreponer al orden existente parcialidades de un nuevo orden, llámense vías elevadas, redes subterráneas, por ejemplo. En este contexto urbano son los edificios los que cargan de magnetismo a la ciudad.

En Roma, Granada, Córdoba, es la suma de elementos cargados de historia lo que produce admiración, si bien son los hitos arquitectónicos lo que identifican. En Atenas, la historia se resume en la Acrópolis, en Roma, en el Coliseo, en París la torre Eiffel. En contraposición, la nueva ciudad contemporánea anda en busca de sus íconos y en casos como el museo Guggenheim, es suficiente. En otras palabras: toda nueva obra permite múltiples oportunidades y ese caleidoscopio la convierte en un mosaico abierto de expectativas. Ello implica una abstracción a una escala colosal.

Las variadas maneras de dar el primer vistazo al museo Guggenheim son todas impactantes. Desde el aire rompe la verticalidad, lanza destellos de luz, ocupa el borde de la ría y se acurruca dentro de lo existente. Armstrong hace algo parecido con el jazz: rompe la monotonía del conjunto y da lugar al solista que carga de misterio la música. En el caso de Bilbao, un inmenso animal extraño ha recalado junto a la ría y da la sensación que está cómodo ahí y que permanecerá en ese lugar porque si bien es un intruso, tampoco es agresivo. Es diferente, es inquietante, pero es hermoso en su tamaño, en su extrañeza, cual un inmenso dinosaurio reposando. Lo desconocido, lo no codificable, lo sorprendente resulta bello. Si es único, si no es referente, impone sus propios códigos estéticos. Imaginemos un dinosaurio de pie en la avenida Providencia de Santiago: sus quince metros de altura, su piel, su dentadura... Las referencias no alcanzan para dimensionarlo en ningún ámbito de nuestra sensibilidad, con lo que su sola presencia impondrá un nuevo orden. Siendo tan poco codificable es bello simplemente por su existencia.

Algo de ello hay en el Opera House de Sydney, sin embargo se sitúa en la bahía como un velero, y si bien es majestuoso es tan evidente que se trata de un colosal velero o bien una gaviota reposando, que su 
impacto no revela sino lo que imaginábamos. Vale repetir: es majestuoso, pero no sorprende. Gehry entendió lo del dinosaurio. Lo que él hizo magistralmente es acurrucarlo en Bilbao. Agregó el solista a la música.

\section{Cuadros, pintura colgada en paredes}

Rauschenberg es de esos artistas de la vanguardia norteamericana que le dio al arte abstracto de los sesenta del siglo veinte el sustento para su legitimación. Vale aclarar que no se trata de un pintor abstracto, como Mondrian, en que la abstracción es rigurosa, pero sí el pintor pop norteamericano trabaja con las mismas armas: usa la abstracción como procedimiento. Vale decir, abstraer la realidad, descodificarla. Dentro de la corriente pop llevó la abstracción, en este caso collages, fotografías, posters, imágenes de la ciudad, a una congruencia plástica, a una nueva frontera.

En una visita al museo Guggenheim de Bilbao, vemos que en la sala principal de ciento cincuenta metros de largo, cuarenta de ancho y veinte de altura, un cuadro del vanguardista artista norteamericano, de seis metros de largo y tres de altura, naufraga. Vale decir, su impacto visual es ínfimo, no conmueve, no exalta, no aporta emoción ni recogimiento. Conforme: no es una sala adecuada para esa obra pictórica. Necesita otra escala. Sin embargo, sospecho que Las Meninas sí se sostendrían dentro de tamaño espacio. Goya con sus Fusilamientos también lo haría. ¿Materia de contrastes? O bien, ¿no será que Rauschenberg trabajó la misma materia con la que Frank Gehry cincuenta años después diseña el museo de Bilbao?

El tiempo es un verdugo implacable, sobre todo con las pretensiones del arte. Colgar un cuadro ya no es lo mismo hoy día dentro de la diáspora de partículas salpicadas en un campo abierto. Las salas de exposición tampoco respetan los códigos y el arte hoy está dispuesto a exponerse en un basural y desafiarse a sí mismo. El museo Guggenheim desafía a la pintura. La barrera de lo abstracto se rompe, menos mal. Me queda la sensación, luego de visitarlo, de que no debo ir a salas de exposición para recoger sensaciones estéticas, de la misma manera de que no debo entrar a templos religiosos para sentir elevación mística. La excepción confirma la regla, claro, pero sospecho que la música está sonando en otro lado.

La volumetría es exagerada. En ese sentido el Guggenheim es fundamentalista y quiere mandar su mensaje a todos los vientos. Más me asienta su impacto urbano, lo del dinosaurio. Pero su despliegue formal interior es impactante. Gaudí hacía lo mismo. Hay que ir al límite formal. Rauschenberg también: no hay belleza, hay sólo coherencia sensorial. Lo 
hizo Van Gogh: aceleró los colores. Los únicos que no exageran son los científicos: suman dos más dos y llegan a cuatro. Pero ello es otra cosa, otro mundo. Aquí no hay suma, sólo sensación.

Es interesante escuchar de labios del propio Gehry lo que piensa al respecto: "Si se puede trasladar la belleza de las esculturas al edificio... cualquier cosa que haga trasmitir movimiento y sentimiento, ahí es donde se encuentra la innovación en la arquitectura...”

En las salas del museo Guggenheim había expuestas instalaciones de diferentes formatos: pirámides de cubos de acero inoxidable del tamaño de botellas de vino superpuestas conformando montículos que semejaban pirámides; en otra, videos de mujeres desnudas sobre montículos de hielo y música electrónica exaltando la imagen. El formato estaba a tono con los espacios, con los aceros, los cristales y los sinuosos volúmenes que las cobijaban: alter egos. Es a lo más que podían aspirar, un segundo apenas del tiempo de la eternidad espacial de la arquitectura. Enseguida, ingresé a otra sala a contemplar cuadros de formato de dos por dos metros de pintura abstracta de destacados artistas que como tales buscan dar con la tonalidad espiritual de nuestro tiempo. Hay algo de derrota en el esfuerzo: el arte se ha escapado de las salas a las cuales se acude a recibir la señal, aquella esquiva conmoción estética. La tesis es que la ciudad es la abstracción. Saltimbanquis en los semáforos de Santiago de Chile son instalaciones, de la misma manera que un bus de la locomoción colectiva, amarillo y a cien kilómetros por hora, rompe la oscuridad de la avenida Providencia a las dos de la mañana.

No es necesario acudir a salas para palpar hacia donde va el arte, porque el arte que los artistas como Rauschenberg propusieron está abierto. Ya no es cuestión de formato, de tamaño, de elaboración intelectual. El mensaje ya no es sólo coherencia. Todo es bello, todo puede sorprender, hay que saber mirar. Y da la impresión que el pulso de estos tiempos es apostarse en las esquinas de la ciudad a observar lo que nos rodea y ver qué nos puede sorprender. Claro, la pregunta es hoy día: ¿Qué es arte? De hecho ya muchos artistas sostienen que el arte, ese arte de los artistas contemporáneos que exhiben en los museos, agoniza, y buscan, eso sí, también en museos, el pulso de este tiempo en instalaciones de todo tipo que puedan dar una respuesta a la identidad que parece cada vez más esquiva.

Las Torres Gemelas fueron pulverizadas por Boeings en tal vez la instalación más extraordinaria imaginable. Hollywood había coqueteado con tamaña instalación sin poder acercarse a una dimensión de realidad tan devastadora. Lo que ahora puede hacer es, a lo más, reconstruirla. Guar- 
dando las proporciones, el museo Guggenheim es un desafío a esa altura para el arte abstracto. Primero que nada rompe el espacio en que el artista de tela configura su expresión. Cambia la escala, rompe con los códigos y se aleja de la sala blanca, aséptica, donde el arte que se exhibe pueda expresar su mensaje que en su esencia es rupturista y sin condiciones. La tela de Rauschenberg, perdida en la colosal dimensión de la sala, da la sensación de estar lamentando su orfandad, eso de decir: "Existo sólo en mi escenario, dentro de mis condiciones ambientales".

Esa condición lo reduce al recorrido de museo. No lo invalida como obra de arte, porque somos capaces de hacer la abstracción del tiempo; sin embargo entra en los códigos del pasado y se le admira en ese contexto. Velázquez hizo su tiempo y se le admira solemnemente en los museos como la máxima expresión de identidad espiritual del ser de ese tiempo y como tal puede sostenerse en cualquier espacio y puede iluminar todo el tiempo, pero desde una perspectiva de lo ya codificado, de lo ya admirado. La sorpresa es de admiración y no de conmoción e inquietud, que es lo que resulta de la obra que anda en búsqueda de dar con una identidad en el campo de lo desconocido.

Es aún muy prematuro para que Rauschenberg vaya a dar al panteón de los inmortales cuando aún los códigos del arte de estos días manejan más menos los mismos códigos formales y de formato que él utilizaba. Dentro del museo Guggenheim, queda la sensación de que la escala de su obra es insignificante en el contexto de la arquitectura que la cobija, aún más cuando la arquitectura juega con los mismos elementos expresivos. Extrañamente, dentro de la colosal sala en la que cuelga la obra Rauschenberg sólo se sostienen esculturas a la escala del edificio. Vale decir, el museo impone sobre el artista un desafío de escala y en ese contexto da la impresión que Rauschenberg requiere de un espacio a su escala, tal vez un museo.

La sensación es de que Gehry funde la escultura con la arquitectura y que la tela, el formato expresivo de la pintura, con su natural limitación de la tela, no lo hace. Hay en ello un aire de resistencia o bien de identidad que no se siente parte de la nueva proposición ya sea porque no se le dan las condiciones adecuadas o bien porque no puede. Esto es sólo una elucubración, pero sí se palpa en el aire de la ciudad contemporánea que los artistas están frente a un nuevo desafío. Picasso intuyó el asunto de la escala y pintó Guernica. No existía entonces el museo Guggenheim. Pero da la impresión que el cuerpo donde se aloja la pintura, el de la tela, es aquel que la acogió históricamente, salvo aquellas excepciones que confirman la regla. No en vano Calder comenzó a pintar aviones. 
Cabe concluir que el arte se puede manifestar de muy diversas maneras: en museos, en galerías, en la ciudad. Vale decir, sin limitaciones, pero también es una realidad que en este tiempo tiene su identidad y que la ciudad le está señalando un escenario tridimensional desconocido e inquietante.

\section{Las catedrales góticas}

Cómo expresar lo qué lograron los arquitectos del medioevo. Hay que imaginar una grúa elevando una masa de piedra de cinco toneladas a setenta metros de altura en tiempos que la altura media de un edificio no superaba los siete metros. Aquello sí era una "instalación". Obviamente las catedrales deben haber sido motivo de orgullo. Todo una comunidad con un proyecto entre manos, mancomunados espiritualmente para elevarse.

Resulta sorprendente que sin medios tecnológicos se construyeran obras de tal dimensión y complejidad. ¿Voluntad? Fe es la respuesta natural. Pero no es tan así. El tema era de identidad, de ser, y la manera del homenaje era la catedral, y la expresión, un anhelo de altura impregnado de solemnidad.

En aquellos tiempos remotos la ciudad era una voluntad colectiva, y paradójicamente en manos de directores omnipotentes, ya fuesen los papas católicos, los reyes, o los mecenas. ¿Cómo se explica tal incongruencia? El arte. Los artistas que rompen las resistencias a la inmovilidad y dejan el campo abierto al descubrimiento.

¿Por qué la Sagrada Familia en Barcelona crece según la voluntad de un artista muerto hace ya más de cincuenta años? Muerto Gaudí la ciudad de Barcelona está inquieta por lo que su obra aún puede revelar. Pero hay una gran diferencia, hoy día las posibilidades son múltiples: para las ciudades contemporáneas hay un campo abierto, cada edificio que se eleva tiene en sus manos la posibilidad de sorprender. Nunca antes existió tal desafío.

La ciudad contemporánea es libre. El nuevo orden urbano se ha liberado, a la espera de que artistas la inoculen de magia, de abstracción, a lo Gehry, vale decir, de que los edificios se conviertan en esculturas y los espacios en pinturas. No se trata sólo de hacer "edificios" sino más bien de entender un fenómeno que en este momento no se ha desarrollado y que, por lo mismo, no tiene expresión codificada. Es la nueva escala del arte de la que queremos sorprendernos. 